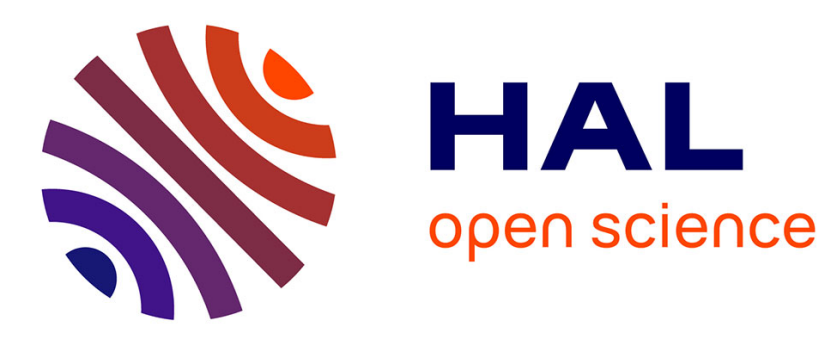

\title{
Francine Masiello, El cuerpo de la voz (Poesía, ética, cultura)
}

José García-Romeu

\section{To cite this version:}

José García-Romeu. Francine Masiello, El cuerpo de la voz (Poesía, ética, cultura). Amerika Mémoires, identités, territoires, 2013, 10.4000/amerika.4359 . hal-03586424

\section{HAL Id: hal-03586424 \\ https://hal.science/hal-03586424}

Submitted on 23 Feb 2022

HAL is a multi-disciplinary open access archive for the deposit and dissemination of scientific research documents, whether they are published or not. The documents may come from teaching and research institutions in France or abroad, or from public or private research centers.
L'archive ouverte pluridisciplinaire HAL, est destinée au dépôt et à la diffusion de documents scientifiques de niveau recherche, publiés ou non, émanant des établissements d'enseignement et de recherche français ou étrangers, des laboratoires publics ou privés. 


\section{Amerika Amerika \\ Mémoires, identités, territoires \\ $9 \mid 2013$ \\ Villes américaines du XXlème siècle : réalités et représentations sociales, culturelles et linguistiques}

\section{Francine Masiello, El cuerpo de la voz (Poesía, ética, cultura)}

Buenos Aires, Beatriz Viterbo, 2013

José García-Romeu

\section{(2) OpenEdition \\ Journals}

Edición electrónica

URL: https://journals.openedition.org/amerika/4359

DOI: 10.4000/amerika.4359

ISSN: 2107-0806

Editor

LIRA-Université de Rennes 2

Este documento es traído a usted por Université de Toulon

\section{UNIVERSITÉ}

IISDE TOULON

Referencia electrónica

José García-Romeu, «Francine Masiello, El cuerpo de la voz (Poesía, ética, cultura)», Amerika [En línea], 9 | 2013, Publicado el 04 diciembre 2013, consultado el 23 febrero 2022. URL: http://

journals.openedition.org/amerika/4359; DOI: https://doi.org/10.4000/amerika.4359

Este documento fue generado automáticamente el 29 septiembre 2020.

(C) Tous droits réservés 


\section{Francine Masiello, El cuerpo de la voz (Poesía, ética, cultura)}

Buenos Aires, Beatriz Viterbo, 2013

José García-Romeu

\section{REFERENCIA}

Francine Masiello, El cuerpo de la vox (Poesía, ética, cultura), Buenos Aires, Beatriz Viterbo, 2013. 
Desde Lenguaje e ideología (1986), los libros de Francine Masiello representan hitos importantes en el estudio de la literatura hispanoamericana. Con este último trabajo que recorre un amplio espectro de obras contemporáneas se repite el placer de leer una propuesta original sustentada en la propia emotividad de la autora, sensibilísima lectora de las voces ajenas. La hipótesis central representa un audaz desafío crítico ya que deja el terreno seguro de la especulación intelectual, del puro análisis verbal y de la interpretación de los tropos para captar, más allá del sentido referencial y de la razón especulativa, los efectos sensibles que la palabra literaria provoca en el cuerpo del lector :

Este libro, que puede considerarse una lectura materialista $o$, si se quiere, una fenomenología del poema o de la obra de ficción, tiene como eje la convicción según la cual la literatura atraviesa nuestros cuerpos, impacta en nuestros huesos y resuena dentro de nosotros, es decir, entra en contacto con nuestros nervios, con nuestros centros de dolor y de placer. La literatura, al transportarnos a una esfera de experiencia tan vitalmente personal, nos permite sentir esa experiencia en carne viva [...]. (p.12)

Desde ese punto de vista, la desfamiliarización de los significados y la descentración del cuerpo, provocadas por la experiencia estética, abren a la conciencia de sí y por ende a la del otro. Si la poesía actual ha de cumplir con un compromiso político, éste se verifica entonces mediante una sensibilidad abierta a la alteridad, una búsqueda de intercambio. Lejos de las conminaciones de los años 60 y 70 que exigían que la literatura incitara directamente a la revolución, el verso llama hoy, sin más (y no es poco), a la comprensión mutua, llenando los huecos del silencio y revelando el rostro ajeno en el roce de las palabras :

No sólo reconocemos el contenido obvio que queda en la superficie del texto; nos dejamos llevar por su estructura formal, por la corriente de significados que se llevan adelante por los silencios y los susurros. Me gustaría pensar en una lectura material de una experiencia fundamentalmente intraducible; llegar a esa otredad por medio de un rodeo, un recorrido de rebotes entre la lengua y la voz. Serán estrategias para disolver las trampas de la razón y detener el orden de la lógica habitual. (p. 221)

El método está puesto a prueba en cada capítulo, con cada uno de los temas tratados (lo popular, el paisaje, la traducción...) : se delimita primero el problema gracias a una reflexión escrupulosa que no carece de valor didáctico (ver por ejemplo el cap. 9 que vuelve sobre la propuesta central con convincente firmeza); se sondea luego la palabra, lírica o narrativa, desde la sensación y la percepción ; se alcanza por fin una conclusión sintética y clara. En cuanto al principal recurso analítico, asumiendo la subjetividad del sujeto crítico, Masiello lo obtiene singularmente de los afectos propios. La exégeta no es 
una contable fría; su emoción es el incentivo de muchas hipótesis, incluso de las más rigurosas :

Los ensayos de este volumen son formas de lucha con el material literario -voz, sonido, ritmo y pulsación- en la medida en que ellos afectan nuestro modo de leer y nos permiten estar enteramente en el presente. En este sentido, los procesos formales que estimulan un compromiso corporal, a su vez dan lugar a un compromiso afectivo e intelectual que constituye un primer paso hacia el pensamiento crítico. (p. 17-18)

Sobre estas premisas, Masiello (que llamaremos a menudo "la lectora" o "la receptora") estudia primero la obra de un precursor (cap. 1). Poeta del jadeo, de la angustia, que regresa a una voz inicial, Leónidas Lamborghini recicla residuos de los textos canónicos argentinos para darles el cuerpo de lo popular, el espesor de una sensación. El sonido se renueva en las emociones elementales, infundiendo a la lectora la conciencia de que hay que aprender a oír las voces soterradas. Esas voces originales son también las de la memoria, que develan en el presente la re-aparición sensitiva del otro, lejano y pasado (cap. 2) : mientras Mirta Rosenberg intenta asir el recuerdo de la madre fallecida y termina anclando paradójicamente a la receptora en el presente de su emoción, Arturo Carrera se esfuerza por reintegrar el pasado de la infancia, explorando las sensaciones residuales. La voz poética, pues, está sujeta al tiempo. Tiempo regresivo de la memoria individual, pero también progresivo del devenir universal : en la obra de Mercedes Roffé, Masiello capta un círculo de gestación, un despertar balbuceante y sensitivo de la sustancia que va llenando el silencio previo, va creciendo, cruzándose con el amplio espectro de la cita y de la reescritura, hasta recuperar el verso y compartir con la lectora, en un impulso ético, su origen esencial y su proyección universal (cap. 5).

5 Ese movimiento ascendente y totalizador se da también en las obras completas (Amelia Biagioni) o reunidas (Diana Belessi) que despliegan, en espesos volúmenes, procesos creativos errabundos y complejos (cap. 3). Por oposición a los tramos y a las rupturas de títulos aislados, la obra integral diseña un camino zigzagueante pero constante. Frente a ese libro contundente, la lectora, intimidada, ensaya estratagemas de postergación antes de entrar en un viaje de entrega mutua : "Descubro que la voz de la obra reunida termina siendo mi interlocutora. Entre las dos, conquistamos el mapamundi, somos expertas en navegación" (p. 78).

6 Masiello registra también los mapas de las voces disconformes : mapa de las identidades femeninas, de los 80 a los 90 (María del Carmen Colombo, Susana Villalba, Verónica Viola Fisher...), que pasan del lirismo comedido al clamor callejero sin dejar de imprimir en la lectora la onda constante del sonido y de la voz (cap. 6) ; mapa del paisaje, de Gabriela Mistral a Hugo Padeletti, que describe la naturaleza como espacio del margen, dedicado a un cuerpo social indeterminado, ajeno a la plasmación de la historia oficial (Juan L. Ortíz). A no ser que ese paisaje ofrezca al ojo su densidad para condensar el cuerpo del sujeto observador (Soledad Fariña). De todos modos, superando las disociaciones de la cultura global, la contemplación del paisaje reúne yo y cosmos, voz-poética y cuerpo-lector (cap. 4). Esta dialéctica entre disconformidad y globalización atraviesa también la ficción (Mario Bellatin, Roberto Bolaño, Diamela Eltit). Por medio del tacto y del cuerpo, las voces narrativas intentan circunscribir la derrota (cuando no se conforman con registrarla) de lo material y de lo humano en una sociedad anestesiada, obsesionada por lo virtual y la sensiblería mediática (cap. 11). Los cuerpos, agredidos por las dictaduras y luego por el neoliberalismo, han quedado en efecto sin voz. Sumidos en un presente indescriptible, ansían recuperar la memoria. En 
ese ambiente de crisis, los poetas del 90 reciclan los objetos kitsch de la cultura de masas (Fabián Casas) o devuelven al mundo su volumen físico mediante la cotidianidad y la fisiología (Martín Gambarotta, Martín Rodíguez, Anahí Mallol). Mientras tanto, muchos narradores (Mario Levrero, Marcelo Cohen, Ricardo Piglia...), descentrados, se anegan en el movimiento. Buscando la posibilidad de un reencuentro, su lengua se hace nómada, constituyéndose en "esperanto de la literatura contemporánea" (p. 278, cap. 12).

7 Es que para Masiello el encuentro de idiomas -esperanto, plurilingüismo o traducciónmanifiesta las cavilaciones de las voces y de los cuerpos. En la traducción empleada como tema de la narrativa (Manuel Puig, María Moreno, Sylvia Molloy), se divisa una zona intermedia en que se disputan identidades confusas y secretas, no solo en lo lingüístico, sino también en lo sexual y en lo nacional (cap. 8). Algo semejante ocurre con la percepción simbólica del Sur (Clemente Riedemann, Juan Pablo Riveros, Cecilia Vicuña...), margen babélico en que las lenguas indígenas -bárbaras al oído de los hombres del norte- chocan con las lenguas europeas encalladas en la ignorancia del medio (cap. 10). En Luisa Futoransky, Babel no es el Sur sino el exilio. En la intersección entre pasado y presente, viaje y pausa, la poeta hace del lenguaje una casa portátil y una brújula. Sus versos acechan el momento del reposo, suspensión que permite el encuentro de las sensaciones y de las voces ajenas, trabadas en el presente de la lectura (cap. 7).

8 La voz poética encarna pues una sensualidad que se lanza hacia el otro desde el individuo y lo local. Invirtiendo la jerarquía de los sentidos, sustituye al poder objetivante de la mirada las sensaciones somáticas. Interrumpe el proceso alisador de la globalización y ofrece la asperidad de un idiolecto, reanudando, por debajo de la deshumanización actual, la posibilidad de un diálogo ético con los lectores.

Aclaremos que para mí El cuerpo de la voz empezó siendo un libro fantasma. Enviado una primera vez desde Francia, nunca llegó... Luego desde Estados Unidos... Tampoco. Como el plazo de entrega de la reseña se acercaba velozmente, rogué a Francine Masiello que me mandara una versión digital. Así lo hizo muy amablemente. El PDF recibido era una curiosa versión de galera que llevaba todavía las señas del proceso de edición: cuadritos, flechas y tachaduras que conformaban el diálogo entre la autora y el editor... Lo imprimí y aproveché cada minuto en su lectura. Acompañando mi nomadismo trivial, entre mi casa y la universidad, el ensayo devino así un texto "para ser leído en el tren", otra manera de atravesar mis paisajes consuetudinarios. Finalmente, el libro mismo me llegó poco antes de que terminara la reseña. Fue un placer tomarlo en mis manos, pasar las páginas, apreciar la ilustración de tapa de Daniel García (círculos concéntricos que se intersectan, insinuando la resonancia entre cuerpo-poético y cuerpo-lector descrita por Masiello). Todo ello me inspira una pregunta última : ¿qué ocurre cuando la poesía deja de leerse en la página y se transfiere a la pantalla, rodillo de textos sin fin, aprehensible sólo por una ventanita lisa, pulcra e inodora? Por ahora, como escribe Borges, yo no hago caso, yo sigo explorando el libro de Masiello : queda mucho por disfrutar. 
ÍNDICE

Palabras claves: poesía

Índice geográfico: Argentina

\section{AUTORES}

JOSÉ GARCÍA-ROMEU

Université du Sud, Toulon-Var 